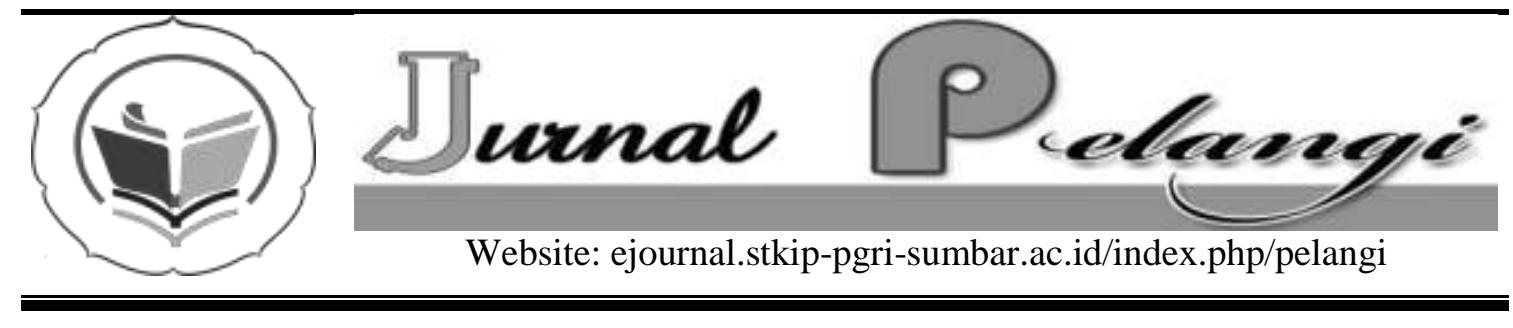

\title{
TIPOLOGI KELOMPOK ENTERPRENEURSHIP MINANGKABAU (Kasus Perempuan Pedagang di Pasar Nagari )
}

\section{Rinel Fitlayeni}

INFO

ARTIKEL

Diterima:

Direview:

Disetujui:

\section{Keywords:}

Typology, group, entrepeneurshi $p$, women traders

\section{Abstract}

The focus of this research to investigate the involment of women in villages in market trading acticity in the economy, especially the old palant. reasonwomen are engaged in trading activities of market economy. The involvement of women in the villlages market means to rebuild the local economy because the forerunner of entrepreneurship. The involvement of women traders provide their own style to the typology groups entrepreneurship in Minangkabau. The methodogy used a qualitative research with hermaneutik interpretative methods, sociology and historical studies. The result show that there are several groups entrepeneurship, first typology is the small traders (one man interprise), there are three categories : strongcapital, trader without capital and wholesalers. The second typology is family enterprise, in the form of commercial business unit or firm. The third typology small enterprise, which distuingishes the family enterprise. This gruop has begun to expand business network not just to traders but also export to other trading outside of the region. 


\section{PENDAHULUAN}

Hal ini dilatar belakangi oleh semakin kuatnya menyambut gerakan otonomi daerah di Sumatera Barat. Ada persolan yang urgen untuk diselesaikan negara antara lain membangun kembali perekonomian daerah melalui pemberdayaan perekonomian masyarakat nagari. Ini bisa dilaksanakan dengan menggali potensi ekonomi nagari melalui pasar nagari. Pasar nagari merupakan sub bagian dari kelembagaan ekonomi masyarakat nagari yang tidak saja mendatangkan pendapatan kas pemerintahan nagari tapi juga sebagai tempat pemasaran produk pertanian masyarakat nagari. Artinya pasar nagari merupakan urat nadi perekonomian masyarakat nagari yang harus digali kembali potensinya. Pasar nagari juga merupakan cikal bakal lahirnya enterpreneurship masyarakat nagari karena terdapatnya perempuan pedagang khusus pada tanaman tua. Berdasarkan argumen diatas, maka perlu diketahui tipologi kelompok enterprenuership di Minangkabau.

Pasar nagari tradisional Minangkabau sebagai tempat pemasaran tanaman tua sejak abad ke 19 telah terlibat langsung dengan mekanisme ekonomi global dan melalui pasar lokal (pasar nagari). Untuk komoditi ekspor di pasar nagari sekarang ini, bentuk produksi yang didasarkan kepada subsisten, petty commodity dan produksi kapitalis, ternyata pada beberapa daerah cenderung didominasi oleh perempuan pedagang (woman traders). Pada hal sebelumnya pekerjaan pedagang selalu identik dengan domainnya pekerjaan laki-laki, terutama untuk komoditi tanaman tua. Tingginya persentase perempuan bekerja di sektor perdagangan juga telah disinyalir oleh Levin, C.E , et. al (1999:6) dalam studinya tentang perempuan pedagang di Accra, Ghana, Afrika. Perempuan terjun ke sektor perdagangan disamping menyeimbangkan tugas-tugas utama mereka dalam pekerjaan rumah tangga, sebagai ibu dalam pengasuhan anak, dan sumber pemasukan pendapatan keluarga.

Perempuan yang berkerja di sektor perdagangan ini mencapai 60 sampai $80 \%$, studi ini juga memperlihatkan peranan penting perempuan meningkatkan pendapatan keluarga sangat dominan. Artinya, perempuan pedagang telah mampu menjadi penopang utama ekonomi rumahtangga mereka, baik sebagai orang tua tunggal, maupun sebagai penopang pendapatan suaminya.

Sebagai seorang ekonom NeoAustrian Weberian, Chamlee-Wright (2000), melakukan studi tentang "Market Woman" di Zimbabwe dan Ghana, yang ingin melihat tentang saling hubungan yang kompleks antara politik, masyarakat dan ekonomi, dengan mengembangkan dan berhasil merangkul konsep "embeddedness" yang kemudian mampu memberikan informasi yang kaya tentang analisis "embededdness" bagi "market women" di Zimbabwe dan Ghana. Ditemukan bahwa hambatan sosial-ekonomi, budaya, politik telah menyebabkan entrepreneur perempuan susah untuk berkembang, dan bahkan sama sekali tidak memberi tempat bagi perempuan untuk berhasil di kota Harare. Dikatakan bahwa di Zimbabwe, diantara orang-orang Shona yang diteliti, adalah masih umum bagi si pelamar lakilaki untuk menawarkan keluarga bakal calon istrinya pada "Labola", yaitu untuk membayar harga diri: "calon suami diharapkan untuk memberikan pengorbanan yang berarti untuk keluarga calon istrinya.

Selanjutnya Wright mengemukakan, Karena Implikasi ekonomi dari perkawinan, bagi keluarga si perempuan--tidak seperti matrilineal society dimana sesudah perkawinan itu 
sama sekali masih mungkin perempuan untuk terus berkontribusi secara ekonomi pada keluarga dimana ia dilahirkan-- disekitar wilayah Shona, antara keluarga dan harga diri menjadi hal yang kedua (sekunder) setelah ia menikah. "Labola" kelihatannya dapat dibayar dalam masyarakat Shona, karenanya dipandang sebagai suatu kompensasi bagi keluarga perempuan untuk kehilangan materi yang mereka derita sesudah menikah, karena diberikan pada "Labola". Sehingga dikatakan bahwa implikasi sosial dan politik dari fenomena yang dikondisikan secara ekonomi ini adalah amat besar. Otonomi politik dan ekonomi perempuan, kapasitasnya untuk berespon pada penyalahgunaan atau pengabaian oleh suaminya dan kontrol si perempuan atas sumberdaya yang dimilikinya dan anak-anaknya semuanya sangat ditentukan oleh labola yang dibayar dan membentuk perkawinan mereka.

Sehingga Labola juga bertindak, sebagai penghalang pada perkembangan dinamika kelompok perempuan entrepreneur di Zimbabwe dan Ghana (Wright, 2000 dalam Boettke dan Storr, 2002).

\section{METODE PENELITIAN}

Penelitian ini mengarah pada pendekatan kualitatif (qualitative approach), dengan informasi yang bersifat subyektif dan historis. Untuk maksud yang demikian, penelitian ini menggunakan strategi studi kasus, dengan pertimbangan bahwa penelitian ini memberikan peluang yang sangat kecil bagi peneliti untuk mengontrol gejala atau peristiwa sosial yang diteliti, disamping penelitian yang dilakukan adalah menyangkut peristiwa atau gejala kontemporer dalam kehidupan yang rill (Yin, 1996). Penelitian ini menggunakan dua jenis data yakni data primer dan data sekunder. Data primer merupakan data yang diperoleh dari hasil wawancara mendalam (indeep interview) dengan perempuan pedagang dengan menggunakan catatan lapangan dan pedoman wawancara. Data sekunder adalah data dan dokumen yang diperoleh dari instansi terkait seperti Dinas Koperindag, Dinas pertanian, BPS dan lainnya yang dapat memberikan sumber informasi kelompok enterprenuership di Minangkabau. Adapun teknik pengumpulan data yang digunakan adalah observasi, dan wawancara mendalam (indeep interview) dengan menggunakan alat perekam dan membuat pedoman wawancara untuk mentipologikan kelompok enterprenuership di Minangkabau

Penelitian ini dilaksanakan di pasar nagari Tabek Patah kabupaten Tanah Datar, di pasar nagari Baso kabupaten Agam, dan pasar nagari Pangkalan kabupaten 50 Kota yang dipilih secara sengaja (purposive sampling) dengan alasan ketiga pasar ini merupakan pasar nagari yang menggelar komoditi eksport utama Sumatera Barat dalam perdagangan komoditi tersebut ditemukan banyak perempuan pedagang, sementara di pasar nagari lainnya cendrung di dominasi oleh kaum lakilaki.

\section{Tipologi Kelompok Enterpreneurship Minangkabau}

Merujuk kepada Westerholm model (2007) dan Sule (2009) terdapat lima tingkat kelompok enterpreneur yang mencerminkan perkembangan bisnis yang ditekuni oleh pelaku bisnis. Pertama adalah pedagang kecil atau usaha kecil (one man enterprise. Kedua adalah Pedagang antar pasar nagari (toke) atau kelompok bisnis family enterprise, ketiga pedagang besar tingkat tingkat kabupaten (small enterprise), keempat pengusaha Minangkabau yang tergabung dalam organisasi KADIN, atau kelompok bisnis 
yang berskala menengah (mediumscale enterprise) yang cikal bakalnya dari perempuan pedagang di pasar nagari, dan kelima adalah kelompok pedagang besar eksportir (big scale enterprise) pada umumnya didominasi oleh China pada komoditi ekspor.

Di Minangkabau tipe pertama ini disebut pedagang kecil keliling (fendor) yang datang berdagang dari pasar nagari yang satu ke pasar nagari yang lainnya. Hasil penelitian memperlihatkan bahwa tipologi pedagang kecil sebagai one man enterprise dapat dibedakan atas tiga kategori yakni: Pedagang bermodal kuat, pedagang tanpa modal (cingkariak), dan pedagang besar (palantuak). Untuk lebih jelasnya lihat table di bawah.

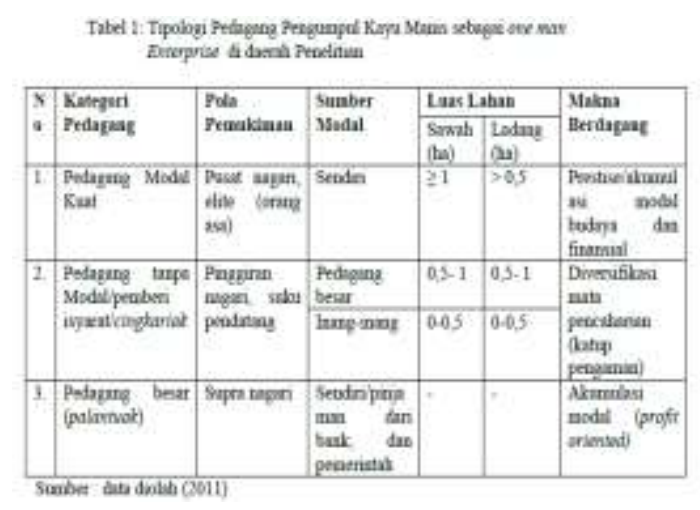

Tabel 1 di atas memperlihatkan bahwa pedagang dengan modal kuat pada umumnya bermukim di pusat nagari dan mereka menjadikan pekerjaan berdagang kayu manis sebagai prestise dan berusaha memupuk modal budaya dan modal kapital. Berbeda dengan pedagang tanpa modal yang lebih dikenal dengan "pemberi isyarat" atau cingkariak, mereka umumnya bermukim di pinggiran nagari, sumber modal sebagian besar merupakan dari pedagang besar dan dari pinjaman inanginang, tetapi makna berdagang bagi mereka adalah untuk melakukan diversifikasi usaha dalam kerangka katup pengaman ekonomi rumah tangga mereka. Kategori pedagang besar (palantuak) pola pemukimannya di supra nagari, memiliki modal sendiri dan makna berdagang bagi mereka adalah untuk keuntungan atau berorientasi keuntungan. Pedagang besar kabupaten dalam menentukan harga akan bertindak secara rasional dengan tujuan untuk melakukan akumulasi modal, pertimbangan rasional ekonomi dengan mengutamakan keuntungan yang lebih besar, ketimbang solidaritas sosial dengan pedagang di bawahnya. Sedangkan pedagang pengumpul pasar nagari dalam menentukan harga lebih terbelenggu oleh hubungan-hubungan sosial dengan petani kayu manis. Motif pengambilan keuntungan bagi pedagang pengumpul pasar nagari untuk tujuan akumulasi modal lebih kecil dari motif membangun jaringan kerja atau hubungan baik dengan petani.

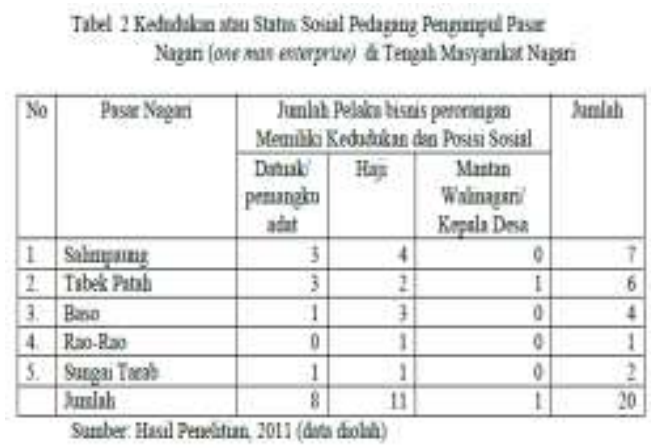

Berdasarkan tabel 2 di atas dapat dikemukakan bahwa pedagang pengumpul pasar nagari yang telah menjadi kaum elite nagari, kemudian mendapat promosi untuk menduduki jabatan dan posisi penting di tengah masyarakat nagari. Ada 8 orang (17 persen) pedagang pengumpul pasar nagari memangku gelar Datuak dan pemangku adat, paling banyak di pasar nagari Salimpaung dan Tabek Patah. Selanjutnya, memperoleh gelar haji sebanyak 11 orang (23 persen) yang paling banyak di pasar nagari Salimpaung, Baso dan Tabek Patah. Kemudian ada satu pedagang pengumpul di pasar nagari yang pernah menjabat sebagai mantan wali nagari Tabek Patah. Apabila dilihat per nagari, jumlah 
pedagang yang memiliki kedudukan dan posisi sosial politik di tengah masyarakat nagari sangat dominan, adalah di nagari Salimpaung, ada 7 orang (58 persen) pedagang pengumpul kayu manis di pasar nagari memiliki kedudukan dan posisi sebagai Datuak, dan Haji (Alim Ulama). Di nagari Tabek Patah terdapat 6 orang (100 persen) pedagang pengumpul pasar nagari memiliki simbol-simbol sosial ekonomi yang menguntungkan praktek bisnis mereka, karena mendapat kepercayaan dan kekuatan sosial dalam menghadapi petani kayu manis dalam transaksi kayu manis di pasar nagari. Di nagari Sungai Tarab ada 2 orang (50 persen) pedagang pengumpul yang memiliki gelar Haji, yang diyakini sumber kepercayaan masyarakat untuk menarik pelanggan petani kayu manis untuk mau menjual kayu manis kepada pedagang yang bertitel haji ini. Titel haji bagi pedagang memperlihatkan simbol-simbol sifat jujur, taat beribadah dan tidak akan mau melakukan dalam berdagang dan terhadap mitra bisnisnya. Titel haji juga akan memberikan kedudukan sosial ekonomi mereka di tengah masyarakat tergolong kepada orang yang ekonominya mampu atau memiliki kekayaan yang berlebih dari masyarakat biasa. Sehingga, salah satu tanda sukses anggota masyarakat nagari adalah apabila sudah beribadah haji ke Mekah, apalagi bila pergi haji lebih dari sekali. (wawancara 29 Juli dengan H. Bactiar, 72 tahun).

Jabatan Datuak dan pemangku adat serta titel haji merupakan simbolsimbol yang besar maknanya bagi pedagang pengumpul di pasar nagari untuk kontinuitas bisnis kayu manis mereka di tengah masyarakat nagari. Jabatan Datuak memiliki konsekwensi bahwa pedagang pengumpul memiliki keuntungan sosial ekonomi dalam bisnis, karena dengan sendirinya petani kayu manis yang menjadi anggota kaum atau sukunya akan menjual kayu manis mereka kepada pedagang pengumpul ini. Walaupun petani kayu manis yang menjadi anggota kaumnya atau sukunya akan memiliki posisi tawar menawar (bargaining) yang lemah, tetapi ini adalah kewajiban sosial (ekonomi moral) yang harus dijalani oleh petani kayu manis. Sering dalam transaksi antara pedagang pengumpul pasar nagari dengan petani kayu manis yang memiliki hubungan kekerabatan ini melakukan pembelian, langsung di kebun-kebun petani kayu manis. Realitas ini memperlihatkan dalam transaksi antara pedagang dan petani kayu manis telah terjadi "permainan aspek ruang dan waktu" yang dilakukan oleh pedagang.

Tipologi kedua kelompok enterpreneurship Minangkabau adalah pedagang besar antar nagari (toke) yang telah memiliki usaha keluarga (family enterprise) dalam bentuk unit usaha dagang (UD) atau firma dan $\mathrm{CV}$. Kelompok pedagang supra nagari ini memiliki hubungan bisnis yang kuat dengan pedagang pengumpul di pasar nagari. Pedagang besar antar nagari (toke) yang pada umumnya di dominasi oleh perusahaan keluarga, memiliki jaringan klientisasi dengan pedagang pengumpul di pasar nagari untuk memperkuat penguasaan mereka terhadap harga dan keuntungan perdagangan.

Hasil penelitian menunjukkan bahwa sistem bisnis perdagangan tanaman ekspor yang dimulai dari petani kulit manis; yang hal ini ditipologikan atas tiga yakni: petani panen tidak menentu, petani panen $1 \times 1$ tahun dan petani panen lebih dari 1x 2 tahun, telah menjadi bagian dari sistem bisnis tanaman ekspor yang memberikan sumbangan yang paling besar terhadap persistensi pasar nagari sampai saat ini. Bisnis ini telah dikuasai oleh kelompok 
usaha keluarga (family enterprise) di level pasar nagari dan berkerjasama dengan kelompok pedagang besar kabupaten (small enterprise).

Hubungan pedagang pengumpul di pasar nagari dengan pedagang antar nagari (toke) lebih berbentuk pada hubungan Patron-klien. Pedagang pengumpul tingkat nagari dan kecamatan merupakan pedagang yang menjadi perpanjangan tangan pedagang tingkat kabupaten. Pedagang tingkat kabupaten (supra lokal) bertindak sebagai bapak buah (Patron) dan pedagang pengumpul di pasar nagari bertindak sebagai anak buah (klien), yang sebagian memperoleh pinjaman modal untuk membeli kayu manis kepada petani, kemudian kayu manis yang dibeli oleh pedagang pengumpul tingkat nagari akan dijual kembali ke pada Patronnya dengan harga yang telah disepakati sebelumnya. Seorang Patron memiliki 5 sampai 7 orang klien di pasar-pasar nagari, mereka inilah yang dikategorikan dalam penelitian ini dengan pedagang modal kecil dan pedagang tanpa modal (pemberi isyarat). Para pedagang yang membentuk hubungan Patron- klien inilah yang membentuk jaringan (network) berkelompok. Artinya ada kelompok-kelompok (clique members) pedagang kayu manis untuk menghadapi pembelian kayu manis petani di pasar nagari. Kelompok-kelompok pedagang inilah yang melakukan transaksi di pasar dengan menekan harga serendah mungkin, agar memperoleh keuntungan besar, dengan cara membuat penawaran berkelompok.

Kelanggengan bentuk hubungan patron-klien diantara pedagang kayu manis ini sangat tergantung kepada pemupukan saling percaya (trust) diantara mereka. Kesetiaan seorang klien sangat tergantung kepada pertama: seberapa besar modal untuk membeli kayu manis di pasar nagari pada setiap kali dibukanya pasar nagari dapat diberikan oleh patronnya, semakin besar pinjaman modal dapat diberikan, maka semakin terikat seorang klien kepada patronnya dan semakin kokoh jalinan perdagangan mereka. Kedua: seberapa besar selisih margin yang diberikan oleh Patron terhadap kliennya, semakin besar marginnya semakin besar keuntungan yang akan diperoleh klien dalam pembelian kayu manis kepada petani, sebab para klien ini harus juga memelihara hubungan baik (klientisasi) dalam bentuk relasi sosial dengan petani kayu manis, agar petani kayu manis terikat dan mau menjual kayu manisnya kepada klien ini, dengan cara membeli kayu manis dengan harga yang wajar menurut petani. Bahkan dalam hubungan ini juga terjadi permainan aspek ruang antara pedagang dengan petani kayu manis. Ketiga: seberapa besar perhatian patron yang diberikan kepada kliennya dalam menjaga hubungan sosial (social relationship) mereka dengan memberikan hadiah-hadiah pada saat hari-hari besar keagamaan, seperti pembagian infak, zakat, daging korban, kado pesta pernikahan anak klien, bantuan pembangunan mesjid dan mushalla di kampung klien, dan kunjungan-kunjungan pada saat-saat waktu tertentu untuk memberikan penguatan kepada kedudukan sosial dengan para klien dan releasi sosial interpersonal (klientisasi).

Dari hasil penelitian Patron yang paling besar jaringannya adalah $\mathrm{H}$. WN (60 tahun) dari Simpuruik Batu Sangkar, WR (42 tahun) dari Nagari Salimpaung, dan CN (59 tahun) dari Payakumbuh. Jaringan kerja yang dibangun oleh $\mathrm{H}$. WN hampir mencakup semua pasar nagari, sedangkan CN (Payakumbuh) jaringan kerjanya hanya pada tiga pasar nagari yakni Baso, Tabek Patah, dan Salimpaung, untuk pasar nagari Rao-Rao dan Sungai Tarab dikuasai oleh H. WN 
dan UD. ML, WR (42 tahun) hanya memiliki jaringan kerja di pasar Baso, di pasar nagari lainnya, WR relatif kurang dipercayai karena dianggap sering mengecewakan kliennya, sehingga WR lebih banyak memperoleh kayu manis dari luar kabupaten Tanah Datar seperti di Baso, dan Matur kabupaten Agam.

Dengan adanya relasi sosial interpersonal terutama dalam bentuk klientisasi antara pedagang pengumpul pasar nagari dengan pedagang besar (supra lokal) di tingkat kabupaten yang membentuk hubungan Patron-klien (reciprocal mutualism) telah menyebabkan para pedagang pasar nagari memiliki kemapanan ekonomi yang lebih di tengah masyarakat nagari. Kedudukan mereka sebagai orang kaya di nagari, telah menyebabkan mereka memiliki pengaruh besar dalam pengambilan keputusan yang menyangkut dengan kepentingan masyarakat nagari. Fenomena ini sesuai dengan yang diindikasikan oleh Evers (1994), bahwa pedagang dalam menghadapi petani di desanya menghadapi dillema tidak hanya berorientasi mengakumulasi modal tetapi juga harus menjaga citranya di tengah masyarakat dalam bentuk melakukan akumulasi modal budaya. Di samping itu pedagang juga harus berbagi keuntungan dengan masyarakat sekitarnya dalam bentuk memberi sumbangan atau menjadi donatur dalam berbagai kegiatan kampung (hubungan klientisasi). Namun dalam bertransaksi dengan petani, ekonomi moral pedagang terlihat "sangat tipis", sementara ekonomi moral petani lebih kental terlihat.

Tipologi ketiga dari kelompok enterpreneur Minangkabau untuk bisnis tanaman ekspor adalah pedagang besar antar kabupaten (small enterprise). Ciri pembeda dengan kelompok bisnis family enteripse adalah sama-sama mempunyai jaringan bisnis ke pasar nagari, tetapi kelompok small enterprise ini sudah mulai melakukan perluasan jaringan bisnisnya bukan hanya ke pedagang ekspor tetapi juga ke perdagangan ke luar daerah lain, untuk yang terakhir ini belum dilakukan oleh kelompok family enterprise. Pada tipe small enterprise sudah mengikutsertakan orang luar "out sider" dalam mengelola usaha bisnisnya. Jenis usaha yang dilakukan tidak lagi hanya satu macam saja, tetapi sudah merambah ke bentuk usaha lain yang terkadang tidak berhubungan sama sekali (non linkages). Pada wilayah penelitian, tipe kelompok bisnis small enterprise jumlahnya sangat terbatas. Pada kabupaten Tanah Datar, untuk bisnis tanaman ekspor ini hanya terdapat satu usaha yang dikategorikan sudah pada tipe small enterprise yakni H.WN (60 tahun) dengan PT.GKSBO yang bergerak dalam bukan hanya bisnis perdagangan tanaman ekspor tetapi juga dalam usaha air minum alami. Sedangkan pada kabupaten 50 Kota untuk komoditi yang sama adalah $\mathrm{CN}$ (59 tahun), sedangkan untuk komoditi ekspor gambir adalah AM (60 tahun)

\section{KESIMPULAN}

Ada beberapa tipologi enterprenuer yang ditemukan dalam masyarakat Minangkabau. Tipologi pertama adalah pedagang kecil atau usaha kecil (one man enterprise), kelompok ini dibedakan atas tiga kategori yakni : Pedagang bermodal kuat, pedagang tanpa modal (cingkariak), dan pedagang besar (palantuak). Tipologi kedua adalah Pedagang antar pasar nagari (toke) atau kelompok bisnis family enterprise, yang telah memiliki usaha keluarga (family enterprise) dalam bentuk unit usaha dagang (UD) atau firma dan CV. Tipologi ketiga pedagang besar tingkat tingkat kabupaten (small enterprise), 
yang membedakan dengan family enteripse adalah kelompok ini sudah mulai melakukan perluasan jaringan bisnisnya bukan hanya ke pedagang ekspor tetapi juga ke perdagangan ke luar daerah lain.

\section{DAFTAR PUSTAKA}

Damsar, (1997), Sosiologi Ekonomi, PT. Raja Grafindo Persada, Jakarta. , (2005). Tanah Ulayat dan Ketahanan Ekonomi Sosial Budaya Masyarakat Minangkabau, Prosiding Seminar, Balitbang Pertanian dan Yapadi Indonesia, Jakarta.

Effendi, N. (1999). Minangkabau Rural Markets: Their System Rules and Function in the Market Community of West Sumatra, Indonesia, Dissertasi, Fakultat fur Soziologie der Universitat Bielefeld, German.

Graves, Elizabeth, (1981). The Minangkabau Response to Dutch Colonial Role in the Ninetenth Century (Monograph Series) No. 60, Cornell University, Ithaca, New York.

Granovetter, M (1990). The Old and The New Economic Sociology : A History and Agenda dalam Friedland, R and Robertson, A.F, (eds) (1990). Beyond the Marketplace Rathiking Economy and Society, Aldine de Gruyter, New York.

Khan, J. (1974). Economic Integration and the Peasant Economy; the Minangkabau (Indonesia) Black Smith, Dissertation University of London (London School of Economics).

Lubis, Akhyar, (2003). Setelah Kebenaran dan Kepastian Dihancurkan; Masih Adakah Tempat Berpijak bagi Ilmuan, Akademia Press, Yogyakarta.
Manan, Imran, (1995), Birokrasi Modern dan Otoritas Tradisional di Minangkabau (Nagari dan Desa di Minangkabau) Yayasan Pengkajian Kebudayaan Minangkabau, Padang.

Nugroho, H. (2001). Uang, Rentenir dan Hutang Piutang di Jawa, Pustaka Pelajar, Yogyakarta.

Poespoprodjo. (1987). Interpretasi; Beberapa Catatan Pendekatan Filsafatinya, Remaja Karya, Bandung. 